\title{
Are volatile unsaturated aldehydes from diatoms the main line of chemical defence against copepods?
}

\author{
Georg Pohnert ${ }^{1, *}$, Olivier Lumineau ${ }^{2}$, Anne Cueff ${ }^{2}$, Sven Adolph ${ }^{1}$, \\ Christophe Cordevant ${ }^{3}$, Marc Lange ${ }^{3}$, Serge Poulet ${ }^{2}$
}

\author{
${ }^{1}$ Max Planck Institute for Chemical Ecology, Winzerlaer Str. 10, 07745 Jena, Germany \\ ${ }^{2}$ CNRS, INSU, UPM, BP 74, 29682 Roscoff, France \\ ${ }^{3}$ Institut Pasteur de Lille, 1 rue du Prof. Calmette, BP 245, 59019 Lille cedex, France
}

\begin{abstract}
New experiments comparing the effects of 3 species of phytoplankton Prorocentrum minimum Schiller 1933 (PM), Thalassiosira rotula Meunier 1910 strains (TR1) and (TR2), and Skeletonema pseudocostatum (SPC) on the fecundity and egg-hatching rates of Calanus helgolandicus females are described. To further determine the chemical factors causing the inhibitory process related to diatoms, the biological findings were linked with an analysis of aldehydic oxylipins (metabolites derived from the oxidative transformation of fatty acids). Members of this compound class have previously been reported to inhibit copepod egg development. Comparison of the inhibitory properties with results from the chemical analysis, as well as bioassays with synthetic samples using sea urchin eggs as a model system, showed that the observed effect is not restricted to the previously identified volatile aldehydes decadienal and decatrienal but, in fact, depends on a reactive structural element $(\alpha, \beta, \gamma, \delta$-unsaturated aldehyde). In addition, the fatty acid content of the algae was verified with special emphasis on eicosapentaenoic acid (EPA), which is currently under discussion for its metabolic value and defensive potential. Our results demonstrate that only certain diatoms inhibit hatching in copepods and that this effect is independent of the EPA content of the diet. Moreover, saturated aldehydes, like the widely distributed tridecanal, did not affect our assay with sea urchin eggs. Since the observed hatching inhibition, as well as the capability for the formation of reactive aldehydes, is highly species and even isolate dependent, it would appear that no prediction of food quality of certain species can be given without a detailed analysis.
\end{abstract}

KEY WORDS: Phytoplankton · Oxylipin · Diatom $\cdot$ Copepod $\cdot$ Hatching $\cdot$ Inhibition $\cdot$ Activated defence Resale or republication not permitted without written consent of the publisher

\section{INTRODUCTION}

Traditionally, phytoplankton, the bulk of the food that sustains copepods, is considered capable of exerting different secondary effects on its consumers, depending on species and chemical composition. These effects can be either positive (e.g. attractant: Williams \& Poulet 1986; energy supply for growth: Müller-Navarra et al. 2000) or negative (e.g. poisoning: Harada 1999; deterrent: Huntley et al. 1986; anti-proliferative: Lacoste et al. 2001). Food effects on copepod reproduc-

*Email: pohnert@ice.mpg.de tion have been linked to different types of phytoplankton, including dinoflagellates (Ianora et al. 1998, Lacoste et al. 2001), chlorophytes (Støttrup \& Jensen 1990, Koski et al. 1998, Lacoste et al. 2001) and bacyllariophytes (Ban et al. 1997). Diets of these algae can act anti-proliferatively and reduce male and female fecundity, embryonic development or egg hatchability. These recent observations have pointed out the role of algal chemical defences that act exclusively as postingestion signals and mediate demographic responses of copepods under laboratory conditions. Furthermore, they have shown the key position of certain phytoplankton species in this anti-proliferative mechanism. Little is known, however, about both the chemical 

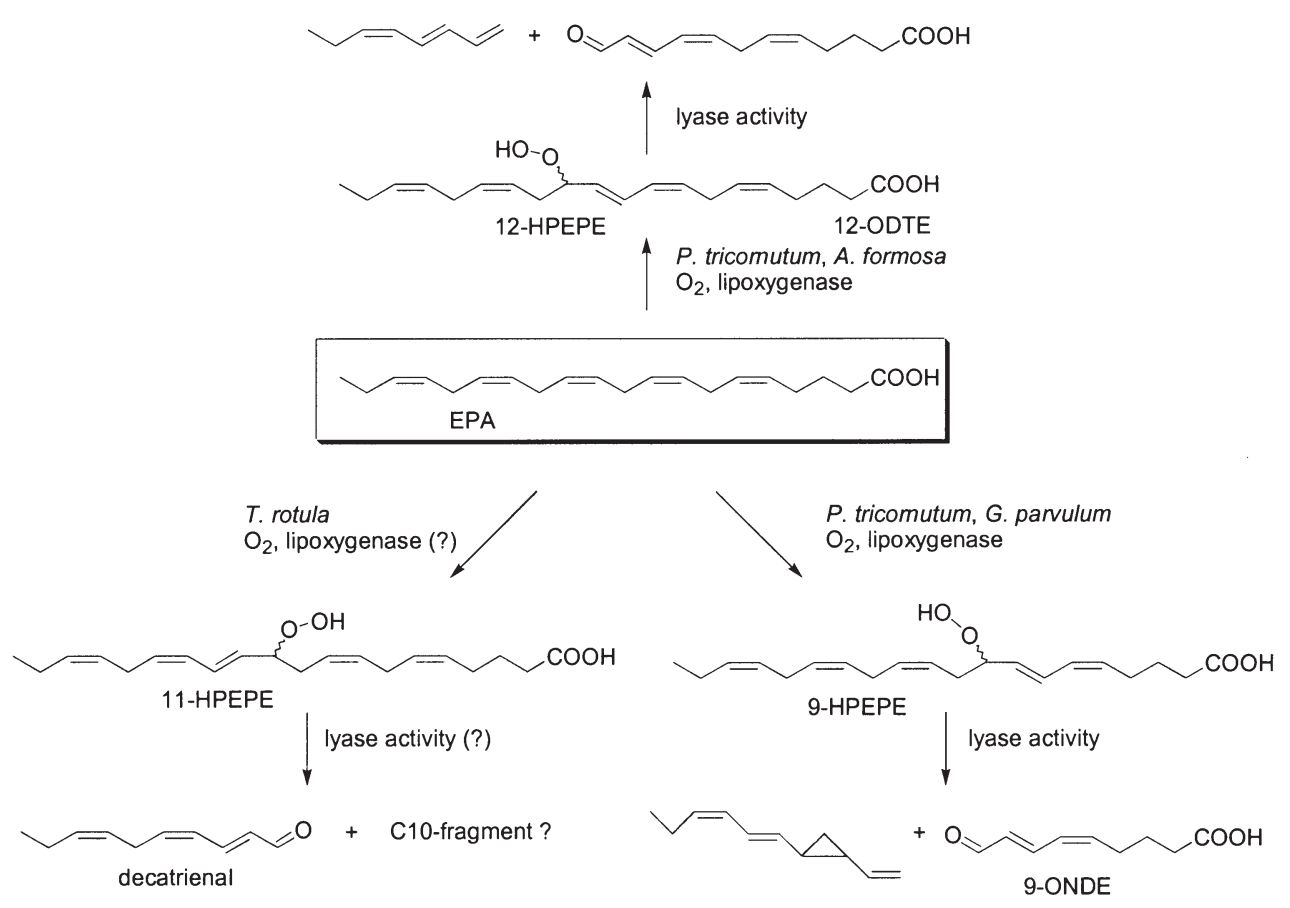

Fig. 1. Lipoxygenase/hydroperoxide lyase-mediated transformation of eicosapentaenoic acid (EPA) in diatoms Phaeodactylum tricornutum, Asterionella formosa, Thalassiosira rotula and Gomphonema parvulum. The indicated products have been isolated as well as their more saturated analogues derived from arachidonic acid (for a review see Pohnert \& Boland 2002)

nature of the factors that have anti-proliferative properties in marine pelagic algae and their ecological relevance.

Miralto et al. (1999) identified reactive volatile aldehydes from the diatom Thalassiosira rotula Meunier 1910 (TR1) with the ability to inhibit egg hatching in copepods. As shown in Fig. 1, these aldehydes, namely $2 E, 4 Z$-decadienal (hereafter decadienal) and $2 E, 4 Z, 7 Z$-decatrienal (hereafter decatrienal) are derived from arachidonic acid (C20:4 n-6) and eicosapentaenoic acid (EPA, C20:5 n-3), respectively (Pohnert 2000). These metabolites thus belong to the oxylipins, a class of compounds that is by definition derived from the oxidative transformation of fatty acids. Their formation is initialised by the action of lipoxygenases, an enzyme class that has been previously detected to be active in numerous diatoms (Fig. 1) (for a review see Pohnert \& Boland 2002). For example, the freshwater diatom Gomphonema parvulum uses EPA as a precursor for the formation of hormosirene, a volatile C11-hydrocarbon released together with a second oxygenated cleavage product 9-oxo-(5Z,7E)-nonadienoic acid (9-ONDE) (Pohnert \& Boland 1996). This oxidative transformation of fatty acids to volatile hydrocarbons and oxygenated acids has also been shown for the diatom Asterionella formosa, which releases octadiene, octatriene and equimolar amounts of 12-oxo$(5 Z, 8 Z, 10 E)$-dodecatrienoic acid (12-ODTE) (Pohnert
2000). What all these transformations, as well as the formation of decadienal and decatrienal from T. rotula (TR1), have in common is that products of the fatty acid transformation are reactive molecules, bearing a characteristic $\alpha, \beta, \gamma, \delta$-unsaturated aldehyde group and are thus potent Michael acceptors (Comporti 1998, Vollenweider et al. 2000). This structural element, shown in Fig. 2, exists in a number of low molecular weight compounds typical for lipid peroxidation products. Molecules belonging to this class are unstable, can form covalent adducts with nucleophiles and are thus often associated with toxicity (van Iersel et al. 1997, Refsgaard et al. 2000). This structural element is also found in other volatile aldehydes from diatoms with unknown biosynthetic precursors, such as 2,4-heptadienal and 2,4-octadienal, reported from Fragilaria sp. and Melosira varians (Wendel \& Jüttner 1996).

Remarkably, diatoms are able to overcome the risk of self-intoxication through these aggressive compounds by using a defensive strategy that acts only when cells

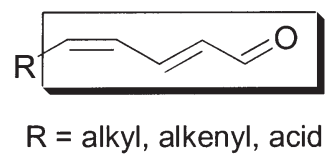

Fig. 2. The reactive Michael acceptor element (framed) found in anti-proliferative metabolites from diatoms 
are wounded (Pohnert 2000, 2002). This 'defence on demand' allows diatoms to build up high local concentrations of these reactive aldehydes in only a few minutes. Since fatty acids are the direct precursors for aldehyde formation, the algae avoid the expense of continuously producing secondary metabolites and can store metabolically valuable fatty acids as their precursors during the absence of herbivores (Pohnert 2000,2002 ). Since the formation of reactive oxylipins seems to be widespread in diatoms, the question arises as to whether this activated defence is a universal property of most or all diatoms, or if it is limited to a few reported examples. The fact that different diatom species do not exert the same inhibitory effect on copepod egg hatching, as shown by Ban et al. (1997) and Lacoste et al. (2001), suggests that the formation of oxylipins is either species dependent or not universally responsible for the inhibitory effect observed.

Studies on the oxylipin impact on growth rates and reproduction of herbivores must also take into account the possible role of fatty acid precursors on these effects. Hence, in addition to the poorly understood effects of oxylipins on zooplankton fitness, EPA is discussed as a non-neutral component of the diet. Recent studies indicate that the EPA content of primary producers is linked to zooplankton growth rates and egg production (Müller-Navarra et al. 2000), and no direct anti-proliferative effect of this acid was observed in tests of the egg hatching success of copepods (Miralto et al. 1999). However, the liberation of free EPA from lipids was found to act as a defence against grazers, and elevated concentrations of this fatty acid were acutely toxic to the anostracan grazer Thamnocephalus platyurus (Jüttner 2001).

The experiments reported below were designed to explore if volatile $\alpha, \beta, \gamma, \delta$-unsaturated aldehydes, known as anti-proliferative principles (Miralto et al. 1999), are the main chemical factors involved in the observed defensive mechanism of diatoms against copepods. The major aim of this paper is to address the hypothesis that diatom species that possess lipoxygenases and

Table 1. Calanus helgolandicus. Carbon concentrations in phytoplankton cells and in copepod diets $\left(10^{4}\right.$ cells $\left.\mathrm{ml}^{-1}\right)$ used for feeding $C$. helgolandicus females. Data are based on Carotenuto et al. (2002)

\begin{tabular}{|lccc|}
\hline $\begin{array}{l}\text { Algal } \\
\text { species }\end{array}$ & $\begin{array}{c}\text { Cell } \\
\text { volume } \\
\left(\mu \mathrm{m}^{3}\right)\end{array}$ & $\begin{array}{c}\text { Carbon } \\
\text { content } \\
\left(\mathrm{pg} \mathrm{cell}^{-1}\right)\end{array}$ & $\begin{array}{c}\text { Carbon conc. } \\
\text { in diet } \\
\left(\mu \mathrm{C} \mathrm{ml}^{-1}\right)\end{array}$ \\
\hline $\begin{array}{l}\text { Prorocentrum minimum (PM) } \\
\text { Thalassiosira rotula } \\
\text { (TR1 and TR2 strains) }\end{array}$ & 1340 & 177 & 0.60 \\
$\begin{array}{l}\text { Skeletonema pseudocostatum (SPC) } \\
\text { Skeletonema costatum (SC) }\end{array}$ & 196 & 122 & 0.85 \\
\hline
\end{tabular}

hydroperoxide lyases involved in the formation of reactive unsaturated aldehydes are those which most severely inhibit copepod egg development. Moreover, the fatty acid content of the investigated phytoplankton species was monitored to identify possible effects of variable EPA contents.

\section{MATERIALS AND METHODS}

Phytoplankton cultures. One dinoflagellate species, Prorocentrum minimum Schiller 1933 (PM, control), and 2 diatom species, Skeletonema pseudocostatum (SPC, Medlin et al. 1991) and Thalassiosira rotula (TR1, Strain CCMP 1647, and TR2, Strain CCMP 1018), were cultured in $\mathrm{K}$ medium (Keller et al. 1987) and $\mathrm{f} / 2$ medium (Guillard \& Ryther 1962), respectively, at $17^{\circ} \mathrm{C}$ and on a 12:12 h light:dark cycle (light intensity: $117 \mu \mathrm{E}$ $\mathrm{m}^{-2} \mathrm{~s}^{-1}$ ) at a maximum cell density of $10^{5}$ cells $\mathrm{ml}^{-1}$. Cell size, carbon cell content and carbon concentration in diets are given in Table 1. Only diatoms belonging to strains TR1, TR2 and SPC were sampled for DNA extraction and genotyping. These 3 strains were cultured in batches in $1 \mathrm{l}$ flask bottles and were used in the late exponential growth phase both to feed copepods and for chemical analyses. Phaeodactylum tricornutum (PT) was cultured in f/2 medium under an identical light and temperature regime in batches $(150 \mathrm{ml})$ and used in the late exponential phase for chemical analyses only.

Morphological examination of diatoms. One $200 \mu \mathrm{l}$ sample per culture for each diatom species (SPC, TR1 and TR2) was fixed with $20 \mu$ l glutaraldehyde (0.5\%), filtered on Nuclepore $0.22 \mu \mathrm{m}$, rinsed with $10 \mathrm{ml}$ distilled water and then dehydrated twice with ethanol solutions (10 min each, at 50, 70, 90, 100\%) prior to critical point drying and gold metallization (Hoepffner \& Haas 1990). Morphotypes of samples were observed using a JEOL JSM-5200 scanning electron microscope (SEM). This study was conducted in order to differentiate SPC from Skeletonema costatum (SC) and TR1 from TR2, 2 diatom species belonging to closely resembling strains.

Genotyping of diatoms. Diatoms (SPC, TR1 and TR2) were prepared for $18 \mathrm{~S}$ rDNA analysis as follows.

Nucleic acid preparation: Genomic DNA was prepared using the Invitrogen DNA isolation system (Easy-DNA kit) in accordance with the manufacturer's recommendations.

PCR amplification: This was carried out on a GeneAmp 2400 PCR system (Perkin Elmer Cetus) using universal primers described previously (Elwood et al. 1985, Sogin \& Gunderson 1987) with minor modifications. The 2 se- 
lected primers - A (5'-CTGGTTGATCCTGCCAG-3') and B (5'-CTTCTGCAGGTTCACCTAC-3') - were complementary to conserved portions of the 18S rDNA region and allowed the complete PCR amplification of the gene (Medlin et al. 1988). A hot-start PCR was performed by adding genomic DNA extract (100 ng) in reaction mixtures containing $1 \times$ GeneAmp buffer I (PE-ABD), each deoxynucleoside triphosphate (Pharmacia biotech) at a concentration of $2.5 \mu \mathrm{M}$, both primers at $10 \mu \mathrm{M}$ and $0.5 \mathrm{U}$ of AmpliTaq Gold (PEABD) in a final volume of $50 \mu \mathrm{l}$. Negative (sterile deionised water) and positive (Saccharomyces cerevisiae genomic DNA) controls were included. The reaction was run for 35 cycles $\left(95^{\circ} \mathrm{C}\right.$ for $1 \mathrm{~min}, 50^{\circ} \mathrm{C}$ for $30 \mathrm{~s}$, $72^{\circ} \mathrm{C}$ for $2 \mathrm{~min}$ ). An initial $10 \mathrm{~min}$ denaturation step at $95^{\circ} \mathrm{C}$ and a final $15 \mathrm{~min}$ extension at $72^{\circ} \mathrm{C}$ were used. The reaction mixture was kept at $4{ }^{\circ} \mathrm{C}$ until use. PCR products were separated on a $1 \%(\mathrm{wt} / \mathrm{vol})$ agarose gel (Quantum biotechnologies) in 1× TBE containing ethidium bromide and visualised under UV light. The amplification product was then directly purified on a Microcon 100 column (Amicon Millipore) before sequencing.

Cycle sequencing: Both strands of the PCR product were sequenced on an ABI Prism 377 DNA sequencer (PE-ABD) with the dRhodamine dye terminators and previously described primers (Sogin \& Gunderson 1987), in accordance with the manufacturer's recommendations.

Sequence data analysis: Sequence data were aligned, manually corrected if necessary, assembled with the Gene Jockey II software (Biosoft) and converted into Pearson format. Sequence interrogation and comparison were achieved using the search program BLAST 2.0 (Altschul et al. 1997) in order to explore all available DNA sequence databases (GenBank, EMBL, PDB and DDBJ).

Computer analysis: The multiple nucleic acid alignment was performed by using Clustal W ver. 1.81 analysis (Higgins \& Sharp 1988, Thompson et al. 1994). The resulting dendogram was generated by the unweighted pair group method using the arithmetic averages (UPGMA). The final phylogeny was obtained by applying the neighbour-joining method (Saitou \& Nei 1987) to the distance and alignment data. This occurred after the alignment step and was a completely independent calculation. The tree file produced by Clustal W was read using Treeview ver. 1.6.6 software (Page 1996).

DNA sequences for the 3 diatoms have been registered in the NIH genetic sequence database, GenBank $^{\circledR}$, under the following numbers: AF462058 (TR1), AF462059 (TR2) and AF462060 (SPC). This study was conducted to check if strains TR1 and TR2 belong to the same species, and to further genetically distinguish SPC from SC.
Bioassays with copepods. Calanus helgolandicus specimens were collected twice a week offshore Roscoff $\left(48^{\circ} 45^{\prime} \mathrm{N}, 3^{\circ} 58^{\prime} \mathrm{W}\right.$, in the Western English Channel, France) from February to July 2001, by towing a $500 \mu \mathrm{m}$ mesh plankton net obliquely from 20 to $0 \mathrm{~m}$. This copepod species was chosen because female reproduction does not require re-mating. Samples were transported within 1 to $2 \mathrm{~h}$ to the laboratory, where adult, sexually mature females (40 to 100 in total for each experiment) were sorted and placed one by one over $24 \mathrm{~h}$ in dishes containing $100 \mathrm{ml}$ of $0.22 \mu \mathrm{m}$ filtered seawater in order to estimate initial fecundity and hatchability (Laabir et al. 1995). Then, 10 to 20 batches of 4 females each were transferred to new dishes with $100 \mathrm{ml}$ filtered seawater enriched with one of the 4 algal diets (PM, SPC, TR1 or TR2) at a cell density of $10^{4}$ cells ml-1 in the copepod incubators. The initial carbon food concentrations in dishes are given in Table 1. Females were transferred to dishes with algal diets renewed daily during the $8 \mathrm{~d}$ incubation periods. Egg production and hatching rates were estimated following the techniques of Laabir et al. (1995). Hatching rate was determined by incubating a new mixture of 30 to 100 freshly spawned eggs for $48 \mathrm{~h}$ in crystallising dishes containing $5 \mathrm{ml}$ of filtered seawater (Laabir et al. 1995). Temperature during all incubations was set at $17^{\circ} \mathrm{C}$.

Bioassays with sea urchin eggs. Sea urchin eggs were used for bioassays since they are routinely available to rapidly screen inhibition of cell division during toxicity tests (Pesando et al. 1990) and since they can be obtained in large number and develop synchronously, 2 characteristics which are not found in copepod zygotes. The effect of the following substances on the embryonic development of the sea urchin Sphaerechinus granularis was examined: Taxol (1 mg ml${ }^{-1}$ in methanol) as a positive control; decadienal ( $1 \mathrm{mg} \mathrm{ml}^{-1}$ in DMSO) as a diatom-derived metabolite with known properties (Miralto et al. 1999); and 3 synthetic oxylipins, identified from diatoms, for structure activity testing (HPETEs, synthetic sample prepared by lipoxygenase-mediated oxidation of arachidonic acid followed by HPLC purification; $1 \mathrm{mg} \mathrm{ml}^{-1}$ in methanol) (Hombeck 1999), 12-ODTE $\left(0.5 \mathrm{mg} \mathrm{m}^{-1}\right.$ in phosphate buffer, $0.05 \mathrm{M}$ $\mathrm{pH}=7$ ) (Pohnert 2000) and tridecanal $\left(1 \mathrm{mg} \mathrm{ml}^{-1}\right.$ in methanol) (SIGMA). Eggs were fertilised following the technique of Meijer et al. (1991). Newly fertilised eggs were placed in $100 \mu \mathrm{l}$ filtered seawater with increasing concentration of synthetic probes at a constant temperature of $20^{\circ} \mathrm{C}$. Observations of the proportions (\%) of first egg cleavage at $3 \mathrm{~h}$ and of the gastrula stage at $24 \mathrm{~h}$ were performed for each compound. Preliminary tests allowed us to evaluate the concentration effects of various buffers or co-solvents (filtered seawater, methanol, DMSO or phosphate buffer) used to dissolve the test compounds. The solvent systems were used at concentrations below 
their intrinsic threshold inhibition, corresponding to $2.5 \%$ (DMSO), $4 \%$ (methanol) and 12\% (phosphate buffer) per volume of seawater, respectively.

Analysis of volatiles. For routine analysis of volatiles, $50 \mathrm{ml}$ of a culture in the late exponential growth phase (ca. $10^{7}$ cells) were concentrated by centrifugation followed by redilution to $3 \mathrm{ml}$. For SPC, the cell density required for the detection of heptadienal was ca. $3 \times$ higher. The samples were transferred to $5 \mathrm{ml}$ glass vials and sonicated using four $80 \mathrm{~W}, 5 \mathrm{~s}$ pulses of a B. Braun 1000L sonicator (40 to $60 \%$ cell disruption, judged by light microscopy). The vials were sealed directly after sonication using a Teflon cap. A polydimethylsiloxane-coated $(100 \mu \mathrm{m})$ SPME fibre (SUPELCO) was introduced in the headspace over the medium. Extraction was performed for $10 \mathrm{~min}$ at room temperature. Evaporation of the analytes from the fibre was directly performed within the injection port $\left(220^{\circ} \mathrm{C}\right)$ of the GC-MS (DB225-MS column, Alltech; T-program: $50^{\circ} \mathrm{C}$ [2 min, splitless $]_{;}$ramped with $10^{\circ} \mathrm{C} \mathrm{m^{-1 }}$ to $200^{\circ} \mathrm{C}$ and with $30^{\circ} \mathrm{C} \mathrm{min}^{-1}$ to $280^{\circ} \mathrm{C}$ [2 min]). Unsaturated aldehydes were identified as described (Pohnert 2000); long-chain aldehydes and volatile hydrocarbons were identified by comparison with synthetic (Schotten et al. 1985) or commercially available reference compounds.
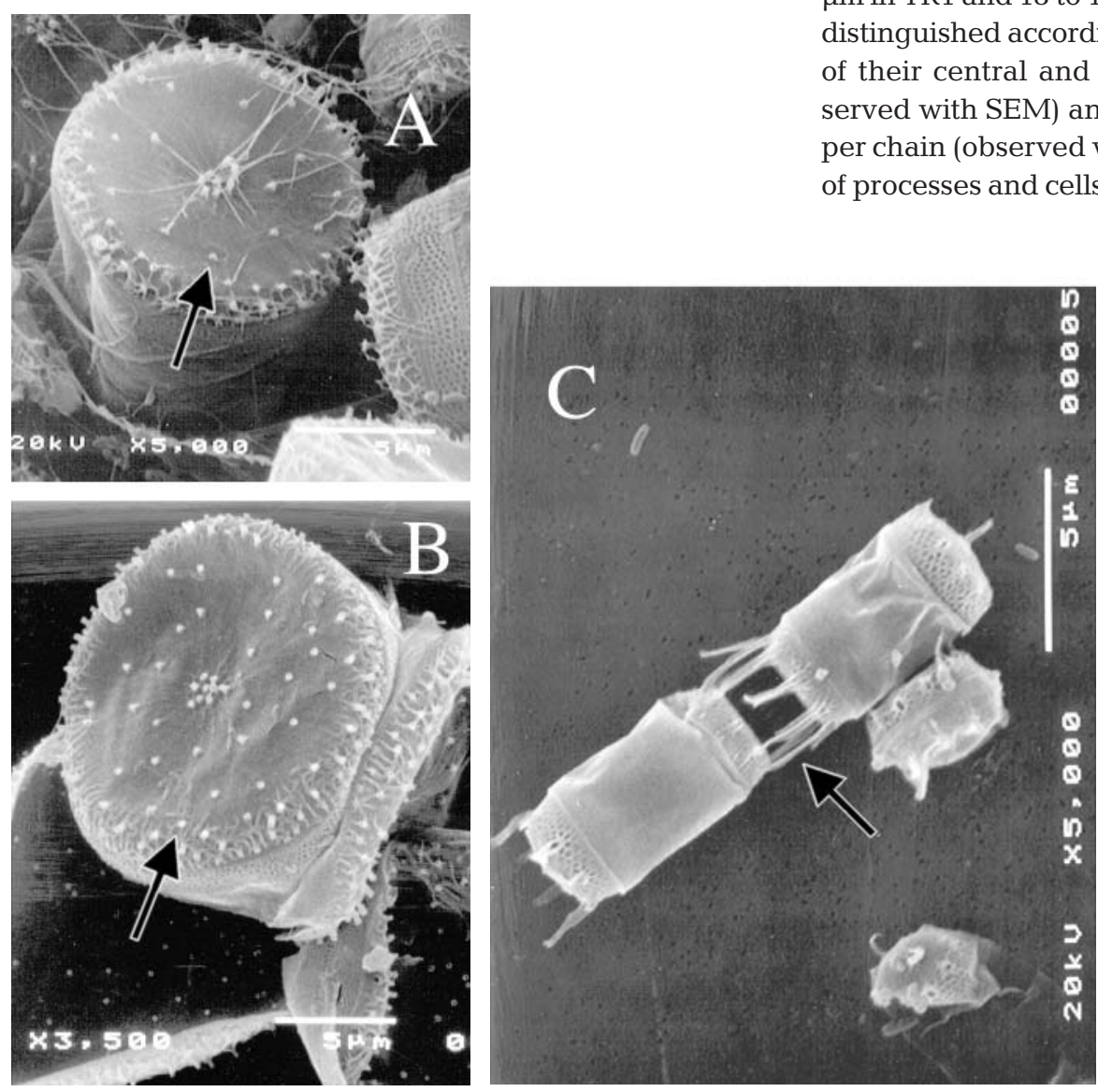

Total fatty acid analysis. The analysis of total fatty acids was performed after trans-esterification following a modified procedure of Lepage \& Roy (1984) (Rodriguez-Ruiz et al. 1998). Before extraction, cells were concentrated to a dense pellet and blotted dry. $\left[{ }^{2} \mathrm{H}_{27}\right]-$ myristic acid at $1 \mu \mathrm{g} \mathrm{mg}^{-1}$ algal wet wt was added as a $10 \mathrm{mg} \mathrm{ml}^{-1}$ solution in ethanol. The algal pellets (20 to $60 \mathrm{mg}$ wet wt) were subsequently taken up in $500 \mu \mathrm{l}$ methanol and treated with $35 \mu$ acetylchloride and $250 \mu \mathrm{l}$ hexane. The samples were sealed and heated for $10 \mathrm{~min}$ to $100^{\circ} \mathrm{C}$. After re-cooling in an ice bath, $500 \mu \mathrm{l}$ water were added and the hexane fraction was directly analysed by GC-MS (DB225-MS column; T-program: $60^{\circ} \mathrm{C}$ [2 min]; ramped with $5^{\circ} \mathrm{C} \mathrm{min}^{-1}$ to $300^{\circ} \mathrm{C}$ [2 min]). The fatty acid methyl esters were identified by their retention time, mass spectra and, if possible, by comparison with commercially available standards. Samples for each species were 3 times replicated.

\section{RESULTS}

\section{Morphotypic identification of diatom species}

The 2 Thalassiosira rotula strains used in this study (TR1 and TR2) are both cylindrical, chain-forming diatoms. The diameters of their flattened valves are 9 to 12 $\mu \mathrm{m}$ in TR1 and 13 to $16 \mu \mathrm{m}$ in TR2. They can be positively distinguished according to the number and arrangement of their central and subcentral strutted processes (observed with SEM) and according to the number of cells per chain (observed with light microscopy). The number of processes and cells per chain is less in TR1 than in TR2
Fig. 3. Comparison of morphotypes among diatoms used in the feeding experiments and for the chemical investigations of oxylipins. SEM pictures of (A) Thalassiosira rotula strain TR1, showing a cluster of central strutted processes and several processes on valve face (arrow); (B) T. rotula strain TR2, for which the number of processes on the valve face is higher (arrow); (C) Skeletonema pseudocostatum SPC, showing the labiate process adjacent to the annulus (arrow), and the marginal ring of split strutted processes (arrow). Scale bars $=5 \mu \mathrm{m}$ 


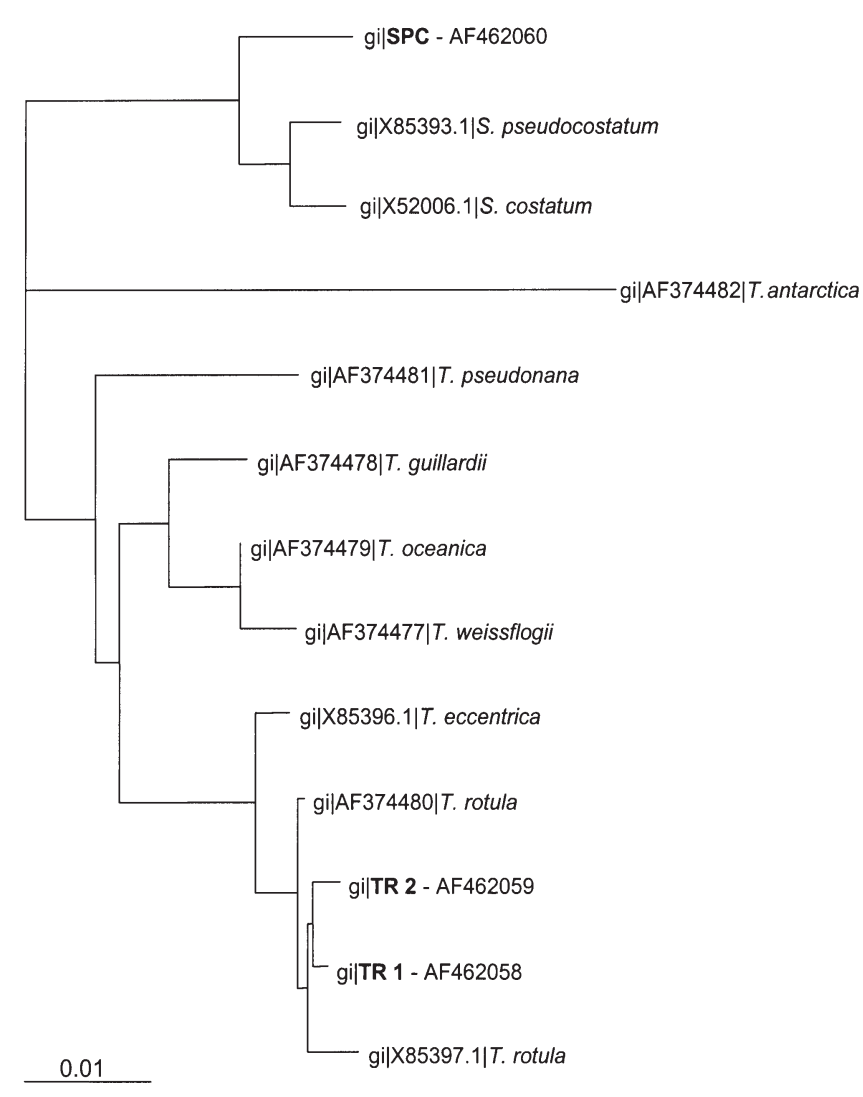

Fig. 4. Diatom phylogeny inferred from 18S rDNA sequence similarities from 10 Skeletonema and Thalassiosira species (GenBank, EMBL, Accession No. AF). Comparison of the distances between nodes of the 3 diatoms (Skeletonema pseudocostatum, SPC; Thalassiosira rotula, strains TR1 and TR2) used in the feeding/reproduction experiments and for the chemical investigation of diatom oxylipins. Distances between nodes of the phylogenic tree are represented by the horizontal component of their separations, given by the scale bar

(Fig. 3A,B). When observed using SEM, SPC can be identified according to the elongated, cylindrical cells with 4 to $6 \mu \mathrm{m}$ diameter forming chains, united by external tubes of strutted processes arranged in 1 marginal ring (Fig. 3C). Comparison of morphological characters between SPC and other Skeletonema species studied with SEM (Medlin et al. 1991), based on the shape of strutted and labiate processes, indicated that our SPC strain resembles both SC (ca. similar split tube for strutted process) and SPC (ca. similar flared tip and labiate process adjacent to annulus).

\section{Genotypic identification of diatom species}

Comparisons between 18s rDNA sequences of TR1, TR2 and SPC are shown in reference to 10 diatom taxa, previously described in the literature (Elwood et al.
1985, Medlin et al. 1996, Armbrust \& Galindo 2001). Although the diatoms TR1 and TR2 have a distinct alignment and thus a slightly different position in the phylogenetic tree, they present 99\% homology with other published sequences of Thalassiosira rotula (Fig. 4). The SPC strain used in this study is a member of another assemblage, unambiguously positioned in a second group, which includes Skeletonema pseudocostatum and S. costatum (Fig. 4). Sequence in SPC presents $98 \%$ homology with a S. pseudocostatum sequence. These DNA sequences are annotated in the NIH genetic sequence data GenBank ${ }^{\circledR}$ under the numbers AF462058, AF462059 and AF462060 for TR1, TR2 and SPC, respectively.

\section{Variation of maternal food effects}

In the copepod Calanus helgolandicus, incubation of females with different types of food was followed by varying biological responses observed in the fecundity and in egg-hatching rates during the $8 \mathrm{~d}$ incubation period (Fig. 5). Previous results have shown that our algal strains are well fed upon by Calanus females (Chaudron et al. 1996). Although ingestion rates were not evaluated in this work, previous results based on faecal pellet production (Chaudron et al. 1996, Kang \& Poulet 2002) have shown that the fecundity response of females fed with SPC were much higher ( $>5$ egg female $^{-1} \mathrm{~d}^{-1}$ ) than in starved females (Lacoste et al. 2001), showing that $C$. helgolandicus females fed sufficiently well on these diatoms. With the dinoflagellate PM (control), egg production rate ranged between 12 and 30 eggs female ${ }^{-1} \mathrm{~d}^{-1}$. With the diatom SPC, egg production was lower and remained below 10 eggs female $\mathrm{d}^{-1}$ or even stopped at Day 7 (Fig. 5A). With the 2 other diatom strains (TR1 and TR2), fecundity also ranged from 10 to 30 eggs female $\mathrm{f}^{-1} \mathrm{~d}^{-1}$. Means of egg production rates with PM, TR1 and TR2 were not significantly different (ANOVA: $F_{\mathrm{C}}=2.84<F_{0.05}=3.79$, df $=7, \alpha=0.05$ ). The mean egg production rate of $C$. helgolandicus fed with SPC was significantly lower than the fecundity responses mediated by PM, TR1 and TR2 (ANOVA: $56.78<F_{\mathrm{C}}<161, F_{\mathrm{C}}>F_{0.05}=3.79$, $\mathrm{df}=7, \alpha=0.05)$. Hatching success of egg spawn by females incubated with PM (Fig. 5B), did not vary with time and remained close to $100 \%$. Similar results were obtained with SPC, which also favoured high hatchability. The egg-hatching response was totally different with the 2 other diatom strains (TR1 and TR2). With TR1, hatching success was strongly inhibited and remained below $65 \%$, with a mean equal to $55 \%$. With TR2, hatching success was much higher (between 67 and 92\%) than with TR1 but lower than PM or SPC. Additionally, it showed a remarkable decrease 
A
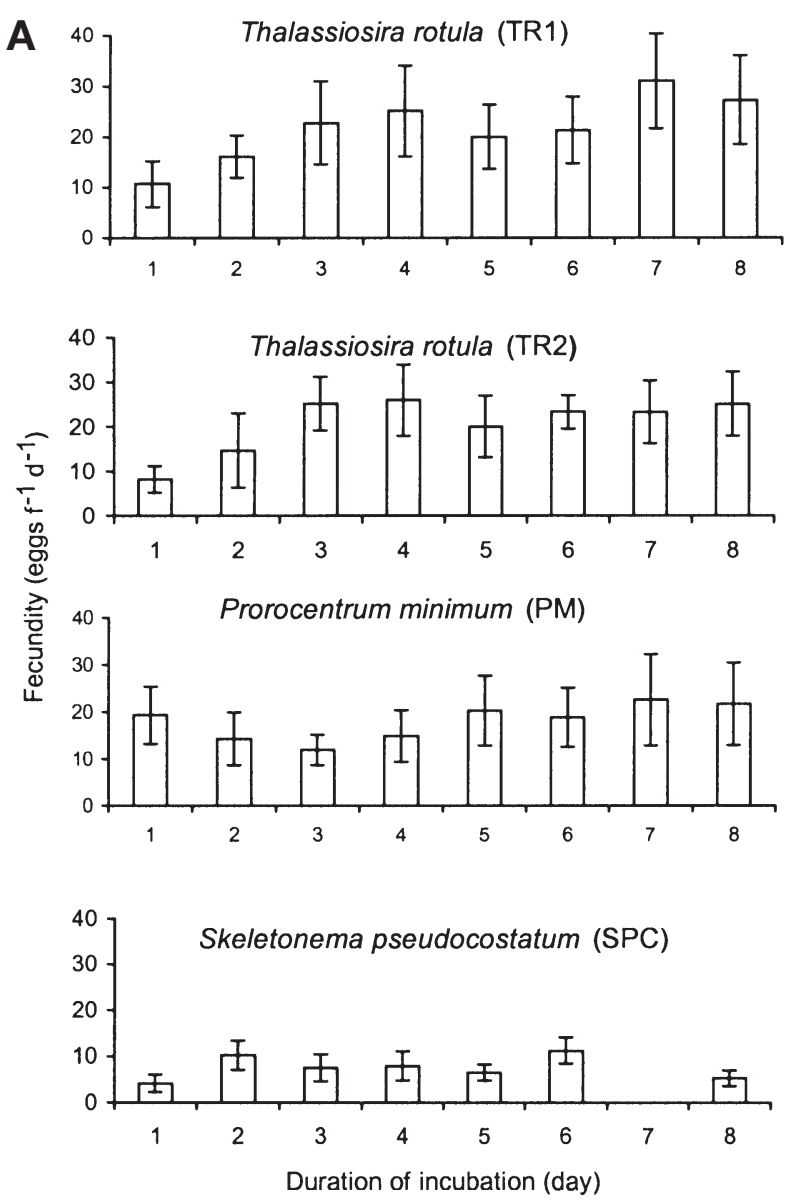

B
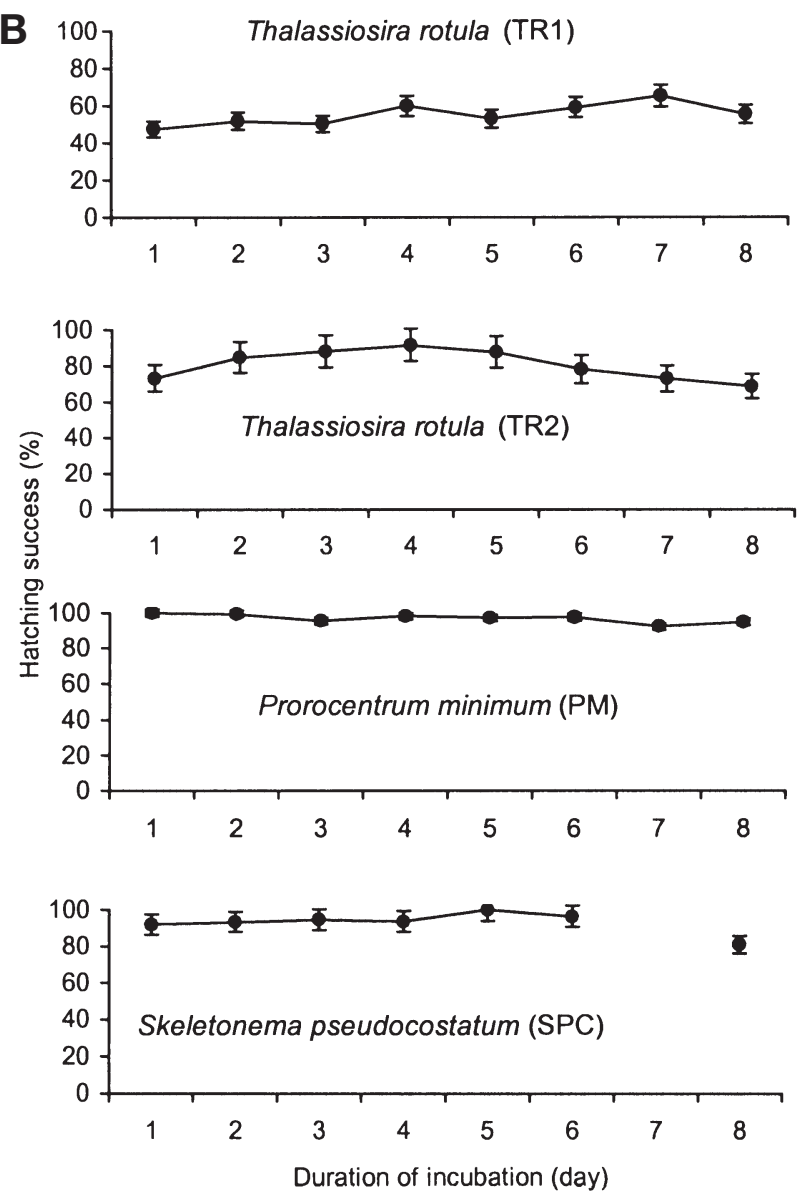

Fig. 5. Calanus helgolandicus. Variations of the reproductive response of the females fed single algal diets. (A) Daily variation of fecundity; (B) daily variation of egg-hatching rate. Values are means \pm SD of 10 replicate measurements

towards the end of incubation. On average, rate of hatching was $81 \%$ with TR2. Percentages of the hatching rates observed with TR1 and TR2 were both significantly lower than with the 2 control diets PM and SPC $\left(\chi^{2}\right.$ test: $\mathrm{df}=21, \chi^{2}{ }_{\mathrm{c}}=23$ to $425>\chi^{2}{ }_{(1-\alpha)}=7.88$; $\mathrm{p}=99.5 \%)$. Percentages of hatching success observed with TR2 were significantly higher than with TR1 $\left(\chi^{2}\right.$ test: $\left.\mathrm{df}=7, \chi_{\mathrm{c}}^{2}=518>\chi_{(1-\alpha)}^{2}=7.88 ; \mathrm{p}=99.5 \%\right)$.

\section{Analysis of volatiles}

\section{Strain TR1}

As reported previously, TR1 produced high amounts of decadienal and decatrienal $\left(0.4\right.$ and $3.9 \mathrm{fmol} \mathrm{cell}^{-1}$, respectively) after wounding by sonication (Pohnert 2000). In addition to these compounds, we found that significant amounts of $2 E, 4 Z$-heptadienal, $2 E, 4 Z$-octadienal and $2 E, 4 Z, 7 Z$-octatrienal were released after disruption of the cells by sonication. The mass spectra of the dienals (McLafferty \& Stauffer 1988) allowed their characterisation together with the use of commercially available or synthetic standards. The structure of $2 E, 4 Z, 7 Z$-octatrienal is suggested by its MS-fragmentation pattern, i.e. $\mathrm{m} / \mathrm{z}$ electron impact $(70 \mathrm{eV})=122$ (11), 104 (10), 93 (60), 91 (74), 81 (79), 79 (43), 77 (10), $68(47), 53(41)$; the high resolution mass spectrum (calculated: $\mathrm{m} / \mathrm{z}=122.0732$; found $\mathrm{m} / \mathrm{z}=122.0734$ ) and the GC-retention time. Besides these reactive Michael acceptors, TR1 produced elevated amounts of tridecanal $\left(21 \pm 8 \mathrm{fmol} \mathrm{cell}^{-1}\right)$ and other long-chain saturated aldehydes, such as dodecanal, tetradecanal and pentadecanal, in minor amounts. In contrast to the lipoxygenase-derived unsaturated Michael acceptors, the production of long-chain saturated aldehydes supposedly follows an independent $\alpha$-oxygenase pathway (Pohnert unpubl. results). All these products were absent in intact cells and their production was initiated only after mechanical wounding of the diatoms (Pohnert 2000). In addition to these aldehydes, traces of C11-hydrocarbons (Fig. 1) were detected in wounded 
TR1. The production of these hydrocarbons is directly linked to the release of non-volatile $\alpha, \beta, \gamma, \delta$-unsaturated aldehydic 9-oxo-nonadienoic acid (Fig. 1) (Pohnert \& Boland 1996). This oxo-acid bears the same structural feature (Fig. 2) as the reactive Michael acceptor decadienal, with proven anti-proliferative properties (Miralto et al. 1999).

\section{Strain TR2}

In strong contrast, isolates of TR2 completely lacked the lipoxygenase-derived $\alpha, \beta, \gamma, \delta$-unsaturated aldehydes, such as decadienal and decatrienal and their lower homologues. Moreover, no volatile hydrocarbons and no aggressive oxo-acids could be detected. In contrast, the wound-activated production of the saturated aldehydes tridecanal and homologues was observed.

\section{Strain SPC}

The lipoxygenase-derived unsaturated Michael acceptors were nearly all absent in this strain and only traces of $2 E, 4 Z$-octadienal could be detected in dense wounded cell suspensions. In contrast, this species showed a very pronounced wound-activated production of long-chain saturated aldehydes with the major products tridecanal, pentadecanal and pentadecenal, and minor amounts of undecanal, dodecanal and tetradecanal.

\section{Phaeodactylum tricornutum}

This diatom (PT), previously reported to strongly inhibit hatching success (Laabir et al. 1999), also completely lacks the unsaturated Michael acceptor aldehydes. However, high amounts of the C11-hydrocarbon hormosirene in addition to the C8-hydrocarbon fucoserratene were detected after wounding. As reported (Pohnert \& Boland 2002), these hydrocarbons are released together with the aldehydic acids 9-ONDE and 12-ODTE, which show the same Michael acceptor structural element as the anti-proliferative aldehydes decadienal and decatrienal (Figs. 1 \& 2). Accordingly, the polar 12-ODTE was also tested and our assays confirmed its inhibitory properties on the development of sea urchin eggs and blastulas (Table 2).

\section{Strain PM}

In strong contrast to all investigated diatoms in this study, PM lacked both the lipoxygenase-derived Michael acceptor aldehydes and the long-chain saturated alde- hydes. No dominant volatiles could be detected, either in fresh extracts of these algae or after wounding. This indicates the complete absence of a wound-activated transformation of fatty acids to reactive aldehydes.

\section{Response of sea urchin eggs to dissolved compounds}

To assess the potential of the identified metabolites that are produced after wounding of diatoms, we selected representatives of 4 different compound classes identified from diatoms to be tested with sea urchin eggs. As an example of a volatile reactive Michael acceptor aldehyde, decadienal was tested. The more polar 12-ODTE, which bears the same reactive structural element (Fig. 2), was selected to test whether the inhibitory properties are specific to decadienal or whether the presence of a Michael acceptor structure is causing inhibition. Further, the most dominant longchain saturated aldehyde, tridecanal, which has been isolated in all investigated diatom species, was selected as a representative of this compound class. To investigate whether metabolic intermediates in the oxidative fatty acid metabolism are active, we selected a hydroperoxy fatty acid mixture derived from arachidonic acid by lipoxygenase-mediated oxidation (hydroperoxyeicosatetraenoic acids HPETEs, compare 9- and 12-HPEPE [hydroperoxyeicosapentaenoic acid]; Fig. 1). The positive control (Taxol) strongly inhibited cell division at concentrations of 3 to $7 \mu \mathrm{mol} \mathrm{l}^{-1}$ (Table 2). This value is in accordance with reported values by Miralto et al. (1999) and proved our experimental set-up to be valid. Responses of sea urchin eggs

Table 2. Sea urchin egg bioassays with a positive control (Taxol) and diatom-derived products $(2 E, 4 Z$-decadienal [Decadienal], hydroperoxyeicosatetraenoic acids [HPETEs], 12-oxo$(5 Z, 8 Z, 10 E)$-dodecatrienoic acid [12-ODTE] and 2E,4Z,7Ztridecanal [Tridecanal]) detected in diatom cultures. For each compound, the threshold concentrations $\left(\mu \mathrm{mol} \mathrm{l^{-1 }}\right.$ ) corresponds to the concentration necessary to reach DL-50 inhibition of cell cleavage at $3 \mathrm{~h}$ and DL-50 inhibition of the gastrula stage at $24 \mathrm{~h}$

\begin{tabular}{|c|c|c|}
\hline $\begin{array}{l}\text { Type of } \\
\text { compound }\end{array}$ & $\begin{array}{c}\text { Threshold after } \\
3 \mathrm{~h} \text { incubation time } \\
\left(\mu \mathrm{mol} \mathrm{l}^{-1}\right)\end{array}$ & $\begin{array}{c}\text { Threshold after } \\
24 \mathrm{~h} \text { incubation time } \\
\left(\mu \mathrm{mol} \mathrm{l} \mathrm{l}^{-1}\right)\end{array}$ \\
\hline Seawater & $\mathrm{a}$ & a \\
\hline Taxol & 3.2 & 3 \\
\hline Decadienal & 7.3 & 7.3 \\
\hline HPETEs & 24 & 23 \\
\hline 12-ODTE & 9 & 10 \\
\hline Tridecanal & Saturated solution ${ }^{\mathrm{b}}$ & Saturated solution ${ }^{\mathrm{b}}$ \\
\hline \multicolumn{3}{|c|}{$\begin{array}{l}\text { a In seawater controls, } 100 \% \text { cleavage and blastula stages } \\
\text { were observed at } 3 \text { and } 24 \mathrm{~h} \text {, respectively } \\
\text { b Due to solubility problems the effect of this aldehyde } \\
\text { could not be quantified }\end{array}$} \\
\hline
\end{tabular}


to the fatty-acid-derived natural products detected in wounded diatoms varied strongly depending on their structure. The DL-50 threshold with the non-volatile Michael acceptor aldehyde 12-ODTE was reached at concentrations around 9 to $10 \mu \mathrm{mol} \mathrm{l^{-1 }}$ and, therefore, was in the range observed for the volatile decadienal $\left(7.3 \mu \mathrm{mol} \mathrm{l^{-1 }}\right)$. Thus, cell division was seriously inhibited with both reactive Michael acceptors decadienal and 12-ODTE. In addition, the hydroperoxy long-chain fatty acids (HPETEs) that degrade readily to reactive downstream metabolites under the assay conditions also had an effect at more elevated concentrations $\left(\sim 23 \mu \mathrm{mol} \mathrm{l}^{-1}\right)$. Tridecanal, a non-reactive volatile aldehyde identified in all investigated diatoms, showed only moderate activity in our standard assay. The DL-50 threshold was reached at elevated concentrations where problems with solubility arose and prevented further testing. These concentrations, at which cross-reaction with the solvent $\mathrm{MeOH}$ occurs, can be seen as too high to account for a biologically relevant toxicity. We conclude that this ubiquitous aldehyde is unable to inhibit embryonic development.

\section{Analysis of total fatty acid content}

All 3 species were investigated for their total fatty acid and EPA contents. A comparable total fatty acid content for the species used in our experiment was determined by GC integration and comparison with the standard $\left[{ }^{2} \mathrm{H}_{27}\right]$-myristic acid. The amount of total fatty acids was similar in all species. Values for TR1, SPC, PM and TR2 were $6 \pm 1.9,7 \pm 2.1,8.6 \pm 1.6$ and $10.1 \pm 1.4 \mathrm{mg} \mathrm{g}^{-1}$ fresh weight, respectively. The relative amount of EPA, expressed as percent of total fatty acids in diets, was similar for all 4 strains. Values were $17.4 \pm 1.4,19.5 \pm 2,23.5 \pm 2.3$ and $25 \pm 0.8 \%$ in SPC, TR1, PM and TR2, respectively. Other unsaturated fatty acids like C22:6 also did not differ substantially in all 4 strains assayed in this study.

\section{DISCUSSION}

In this study, we explored if the production of reactive volatile aldehydes by algae, as part of copepod diets, can be linked to their ability to cause reproductive failure in copepods. The focus was on the comparison of the properties of algae in bioassays and their chemical analysis, with emphasis on fatty acids and fatty-acid-derived metabolites, compound classes for which anti-proliferative and beneficial effects have previously been identified. In addition, screening of the identified metabolites for anti-proliferative activities using sea urchin eggs as a model system was per- formed. Testing these compounds on sea urchin eggs (Table 2), or diatom extracts directly on copepod eggs (Poulet et al. 1994), or adding reactive aldehydes in the female copepod diets (Ianora et al. 1999) are complementary assays that help to screen for any inhibitory property on cell division in embryos. Recently, Caldwell et al. (2002) have shown that decadienal, tested with other marine invertebrates, also inhibited embryonic development, suggesting that its deleterious activity is neither restricted to sea urchins nor to copepods.

Although the PM, TR1, TR2 and SPC diets were cultured under the same laboratory conditions and were delivered to copepod females at the same food concentration, none of them triggered identical reproductive responses in Calanus helgolandicus. The same trends have been reported earlier by Chaudron et al. (1996) and Laabir et al. (1999). These authors have shown that the dinoflagellate PM as well as several diatoms, including TR1, favour high fecundity, whereas other diatom species, such as SPC, do not. The reason why SPC creates a fecundity decrease in C. helgolandicus females, probably similar to Phaeodactylum tricornutum, has also been discussed (Lacoste et al. 2001). For hatching, variable effects have been found with PM, TR1, TR2 and SPC. Egg viability was greatly reduced with certain diatom diets (TR1, PT: Laabir et al. 1999), while it was high and stable with the dinoflagellate diet (PM) and with other diatom species (SPC). Taken all together, our results add further evidence to the fact that the maternal food effect related to hatching inhibition does not hold across all diatom species. This non-uniform defence mechanism, initially identified in diatoms by Poulet et al. (1994, 1995), was documented by a series of investigations. The concerted effort by 23 investigators revealed 4 different types of effects of diatoms on copepods, including those observed here (Ban et al. 1997). Our studies show that not only different species but also TR1 and TR2, 2 strains belonging to the same diatom species, and differing only minimally in morphology (Fig. 3) and with 99\% genotype identity (Fig. 4), show pronounced differences in their effects on the hatching success. We have tried to link these different reproductive responses to both the fatty acid content and to the ability to form aggressive oxylipins in each alga investigated.

Analysis of the total fatty acids after trans-esterification revealed that the amount of these compounds was comparable in all 4 diets. This similarity was also found for the relative fatty acid composition with respect to EPA. This fatty acid, traditionally known to determine egg production, hatching success and embryonic development in crustaceans and molluscs (Langdon \& Wladock 1981, Jónasdóttir 1994, Xu et al. 1994, MüllerNavarra 1995), was present in the 4 diets offered to Calanus helgolandicus females. Therefore, a depletion 
in EPA could not be responsible for the observed differences in the inhibition of hatching. Moreover, an effect of other, shorter-chain saturated fatty acids can be ruled out, since in none of the administered diets was any polyunsaturated fatty acid depleted compared to the other species. Our present results support the conclusion previously stated by Lacoste et al. (2001) that these essential substrates are not limiting in diatoms and, thus, are not the chemical causes that mediate hatching success.

Because the diets tested (PM, TR1, TR2 and SPC) differed significantly in their inhibitory activity, we have

Table 3. Detected lipoxygenase/hydroperoxide lyase products and long-chain aldehydes in the investigated species. +++ : dominant component $\left(>5 \mathrm{fmol} \mathrm{cell}^{-1}\right)_{i}++$ : major component $\left(5\right.$ to $\left.0.4 \mathrm{fmol} \mathrm{cell}^{-1}\right) ;+$ : traces $\left(<0.4 \mathrm{fmol} \mathrm{cell}^{-1}\right) ;-$ : not detected. 12-ODTE: 12 -oxo-(5Z, $8 Z, 10 E)$-dodecatrienoic acid; 9-ONDE: 9-oxo-(5Z, 7E)-nonadienoic acid

\begin{tabular}{|c|c|c|c|c|c|}
\hline Detected metabolites & TR1 & TR2 & SPC & PM & PT \\
\hline Decatrienal & ++ & - & - & - & - \\
\hline Decadienal & + & - & - & - & - \\
\hline$\widehat{=}=$ & +++ & - & - & - & - \\
\hline$\overbrace{\text { Octatrienal }}^{=}$ & ++ & - & - & - & - \\
\hline Heptadienal & + & - & + & - & - \\
\hline 12-ODTE & - & - & - & - & + \\
\hline $\mathrm{O}_{9-\mathrm{ONDE}}$ & + & - & - & - & +++ \\
\hline Dodecanal & + & + & ++ & - & - \\
\hline Tridecanal & +++ & ++ & +++ & - & - \\
\hline Heptadecanal & + & - & ++ & - & - \\
\hline $\begin{array}{l}\text { Pentadecanal and } \\
\text { pentadecenal }\end{array}$ & - & - & +++ & - & - \\
\hline
\end{tabular}

examined their potential to produce oxylipins, such as the Michael acceptors decatrienal and decadienal, identified earlier as the main chemical hatching inhibitors of Thalassiosira rotula (Miralto et al. 1999). In the present study, we show that the ability of different diatoms to form reactive aldehydes depends on species and isolate. This could account for the drastic difference in their inhibitory properties. Of the 4 diets tested, only TR1 produced the anti-proliferative aldehydes decadienal and decatrienal (Table 3); all other investigated diatom species, as well as PT, for which pronounced reduction of the hatching success had already been documented (Laabir et al. 1999), completely lacked the ability to form these metabolites. A more detailed investigation showed that some diatoms produced other unsaturated and saturated aldehydes upon cell disruption (Table 3). Some of these compounds with structural similarities to decadienal have been found in other freshwater and marine diatoms (Pohnert \& Boland 1996, Wendel \& Jüttner 1996, Jüttner \& Durst 1997, Miralto et al. 1999, Pohnert 2000).

To test whether these fatty-acid-derived compounds can account for an inhibitory effect, we selected 3 additional representative fatty-acid-derived metabolites with different properties for an initial structure-activity evaluation. Since not only the volatile reactive aldehydes like the $\alpha, \beta, \gamma, \delta$-unsaturated aldehydes decadienal and decatrienal were detected in the extracts, but also the polar oxo-acids 12-ODTE and 9-ONDE, which bear the same structural element, we selected 12-ODTE to be tested as it had the advantage of being stable during the whole assay period. Both 12-ODTE and 9-ONDE have the reactive Michael acceptor element but show different membrane permeability and solubility compared to decadienal and decatrienal. As shown in Table 2, the inhibitory property of the polar 12-ODTE was only slightly lower, compared to decadienal. The activity of the oxo-acid could explain why the diatom PT is a highly inhibitory alga (Chaudron et al. 1996, Laabir et al. 1999) even though it lacks the volatile aldehydes decadienal and decatrienal. It produces significant amounts of 9-ONDE and 12-ODTE, and these molecules could account for the observed activity. These observations show that not only do the previously identified volatile aldehydes (Miralto et al. 1999) act as a chemical defence but, more generally, that the presence of $\alpha, \beta, \gamma, \delta$-unsaturated aldehydes (compare Fig. 2) as defensive metabolites is important for inhibition to occur.

To test whether the intermediates in the biosynthesis of these reactive aldehydes (HPETEs; Fig. 1) also act as potential inhibitors, we selected a mixture of these hydroperoxy fatty acids for our assay. These hydroperoxides tend to degrade during the assay period and form a multitude of different reactive oxylipins (Girotti 1998). Indeed, HPETEs and their degradation products 
were also inhibitory but with a threshold above those of 12-ODTE and decacienal. Apparently, a multitude of metabolites derived from the oxidative enzymatic transformation of eicosapentaenoic and arachidonic acid show inhibitory properties, and in the future a detailed structure-activity study will be required.

In contrast to those metabolites that are derived from the oxidative transformation of unsaturated fatty acids, the saturated volatile aldehydes found in all investigated diatoms other than PT seem to have no impact on egg-hatching rates. The most dominant representative in the extracts was tridecanal. When this aldehyde was tested, no pronounced activity was observed even with saturated solutions (Table 2).

Remarkably, TR1 had a significantly higher inhibitory effect on the hatching success compared to TR2. Both isolates also differed in their abilities to form antiproliferative oxylipins via a lipoxygenase-mediated transformation of unsaturated fatty acids (Table 3). TR1 produced high amounts of decatrienal and octadienal in addition to other aggressive oxylipins, such as decadienal, octatrienal, heptadienal and 9-ONDE. In contrast, the less inhibitory TR2 lacked these reactive aldehydes (Table 3). The remaining activity of TR2 might be explained by the presence of other fatty-acidderived oxylipins not identified in this study; hence, a more detailed investigation of this isolate is required. Since even hydroperoxy fatty acids (HPETEs; Table 2) and their degradation products with a high structural variability showed activity, a comprehensive analysis of this compound class is required for TR2. The noninhibitory diatom (SPC) contained very reduced levels of one reactive Michael acceptor, heptadienal, which could be detected only if we submitted dense preparations to chemical analysis. A complete absence of aggressive oxylipins was detected for the dinoflagellate PM. Here, no metabolites derived from the oxidative transformation of fatty acids could be detected in GC/MS and LC/MS measurements. In contrast, the strong inhibitory diatom PT contained elevated amounts of 9-ODTE and 12-ODTE; containing $\alpha, \beta, \gamma, \delta$ unsaturated structures. In summary, the bioassays with oxylipins and the analysis of the content of reactive fatty acid-derived metabolites in inhibitory algae suggest that the presence of fatty-acid-derived metabolites with Michael acceptor properties seems to be a more general criterion for predicting inhibitory properties of diatoms than only the determination of decadienal and decatrienal. Results in Table 3 and the comparison between the inhibitory effects (Fig. 5B; Miralto et al. 1999) of the phytoplankton species PM, SPC, PT, TR1 and TR2 reveal that this aldehyde production and inhibitory effects are diatom species and isolate dependent. This also suggests that caution should be exercised when species are incorrectly differentiated or belong to closely related strains, as illustrated with TR1 and TR2.

A similar case seems to exist for SC and SPC, described by Medlin et al. (1991). Our results (Fig. 2) show that the genotype of our SPC strain presents $98 \%$ homology with Skeletonema pseudocostatum. In fact, these 2 species differ from each other by very subtle morphological characteristics (Fig. 3), which were not considered in our previous work, and thus SPC was not considered a separate species. The other species (SC) used by Ianora et al. (1995) and Miralto et al. (1999) had a strong inhibitory effect on hatching success, whereas SPC used in this study, which lacks reactive aldehydes, had no effect (Fig. 5B). Our present results clarify the discrepancy observed with these 2 Skeletonema species (SC and SPC), which exerted opposite hatching responses, as reported initially by Ban et al. (1997).

These examples further elucidate the chemical reasons why some diatom or non-diatom species or strains are not inhibitory (PM, TR2 and SPC) and some diatoms are (TR1, PT, SC and others; see Ban et al. 1997). The chemical analysis suggests that the anti-proliferative mechanism in diatom species, which results in the inhibition of embryonic development and hatching of their main predators, is more generally dependent on the action of lipoxygenases/hydroperoxide lyases. These transform unsaturated fatty acids into reactive aldehydes that caused inhibition of the embryonic development in model investigations using sea urchin eggs.

Acknowledgements. We are grateful to the sailors at the Roscoff Marine Station for providing the zooplankton and sea urchin samples. We also thank F. Le Gall for keeping our phytoplankton cultures. E. Baldwin and Prof. W. Boland are acknowledged for helpful discussion during the preparation of this manuscript.

\section{LITERATURE CITED}

Altschul SF, Madden TL, Schaffer AA, Zhang JH, Zhang Z, Miller W, Lipman DJ (1997) Gapped BLAST and PSIBLAST: a new generation of protein database search programs. Nucleic Acids Res 25:3389-3402

Armbrust E, Galindo HM (2001) Rapid evolution of a sexual reproduction gene in centric diatoms of the genus Thalassiosira. Appl Environ Microbiol 67:3501-3513

Ban S, Burns C, Castel J, Chaudron Y and 19 others (1997) The paradox of diatom-copepod interactions. Mar Ecol Prog Ser 157:287-293

Caldwell GS, Olive PJW, Bentley MG (2002) Inhibition of embryonic development and fertilization in broadcast spawning invertebrates by water soluble diatom extracts and the diatom toxin 2-trans, 4-trans-decadienal. Aquat Toxicol 60(1-2):123-137

Carotenuto Y, Ianora A, Buttino I, Romano G, Miralto A (2002) Is post-embryonic development in the copepod Temora 
stylifera negatively affected by diatom diets? J Exp Mar Biol Ecol 276(1-2):49-66

Chaudron Y, Poulet SA, Laabir M, Ianora A, Miralto A (1996) Is hatching success of copepod eggs diatom densitydependent? Mar Ecol Prog Ser 144:185-193

Comporti M (1998) Lipid peroxidation and biogenic aldehydes: from the identification of 4-hydroxynonenal to further achievements in biopathology. Free Rad Res 28:623-635

Elwood HJ, Olsen GJ, Sogin ML (1985) The small-subunit ribosomal RNA gene sequences from the hypotrichous ciliates Oxytricha nova and Stylonychia pustulata. Mol Biol Evol 2:399-410

Girotti AW (1998) Lipid hydroperoxide generation, turnover, and effector action in biological systems. J Lipid Res 39: 1529-1542

Guillard RRI, Ryther JH (1962) Studies of marine planktonic diatoms. J Microbiol 8:229-239

Harada K (1999) Recent advances of toxic cyanobacteria researches. J Health Sci 45:150-165

Higgins DG, Sharp PM (1988) CLUSTAL: a package for performing multiple sequence alignment on a microcomputer. Gene 73:237-244

Hoepffner N, Haas LW (1990) Electron microscopy of nanoplankton from the North Pacific central gyre. J Phycol 26: 421-439

Hombeck M, Pohnert G, Boland W (1999) Biosynthesis of dictyopterene a: stereoselectivity of a lipoxygenase/hydroperoxide lyase from Gomphonema parvulum (Bacillariophyceae). J Chem Soc Chem Commun 243-244

Huntley ME, Sykes P, Rohan S, Marin V (1986) Chemically mediated rejection of dinoflagellate prey by the copepod Calanus pacificus and Paracalanus parvus: mechanisms, occurrence, significance. Mar Ecol Prog Ser 28:105-120

Ianora A, Poulet SA, Miralto A (1995) A comparative study of the inhibitory effect of diatoms on the reproductive biology of the copepod Temora stylifera. Mar Biol 121: 533-539

Ianora A, Miralto A, Butino I, Poulet SA, Romano G (1998) First evidence of some dinoflagellates reducing male copepod fertilisation capacity. Limnol Oceanogr 44:147-153

Ianora A, Miralto A, Poulet SA (1999) Are diatoms good or toxic for copepods? Reply to comment by Jónasdóttir et al. Mar Ecol Prog Ser 177:305-308

Jónasdóttir SH (1994) Effects of food quality on the reproductive success of Acartia tonsa and Acartia hudsonica: laboratory observations. Mar Biol 121:67-81

Jüttner F (2001) Liberation of 5,8,11,14,17-eicosapentaenoic acid and other polyunsaturated fatty acids from lipids as a grazer defense reaction in epilithic diatom biofilms. J Phycol 37:744-755

Jüttner F, Durst U (1997) High lipoxygenase activities in epilithic biofilms of diatoms. Arch Hydrobiol 138:451-463

Kang HK, Poulet SA (2000) Reproductive success in Calanus helgolandicus as a function of diet and egg cannibalism. Mar Ecol Prog Ser 201:241-250

Keller MD, Selvin RC, Claus W, Guillard RRL (1987) Media for the culture of oceanic ultraphytoplankton. J Phycol 23: 633-638

Koski M, Klein Breteler W, Schogt N (1998) Effect of food quality on rate of growth and development of the pelagic copepod Pseudocalanus elongatus (Copapoda, Calanoida). Mar Ecol Prog Ser 170:169-187

Laabir M, Poulet SA, Ianora A (1995) Measuring production and viability of eggs in Calanus helgolandicus. J Plankton Res 17:1125-1142

Laabir M, Poulet SA, Cueff A, Ianora A (1999) Effect of diet on levels of amino acids during embryonic and naupliar de- velopment of the copepod Calanus helgolandicus. Mar Biol 134:89-98

Lacoste A, Poulet SA, Cuef A, Kattner G, Ianora A, Laabir M (2001) New evidence of the copepod maternal food effects on reproduction. J Exp Mar Biol Ecol 259:85-107

Langdon CJ, Wladock MJ (1981) The effect of algal and artificial diets on the growth and fatty acid composition of Crassostrea gigas spat. J Mar Biol Assoc UK 61:431-448

Lepage G, Roy CC (1984) Improved recovery of fatty-acid through direct trans-esterification without prior extraction or purification. J Lipid Res 25:1391-1396

McLafferty FW, Stauffer DB (1988) The Wiley NBS registry of mass spectral data. Wiley, New York

Medlin L, Elwood HJ, Stickel S, Sogin ML (1988) The characterization of enzymatically amplified eukaryotic 16S-like rRNA-coding regions. Gene 71:491-499

Medlin LK, Elwood HJ, Stickel S, Sogin ML (1991) Morphological and genetic variation within the diatom Skeletonema costatum (Bacillariophyta): evidence for a new species, Skeletonema pseudocostatum. J Phycol 27:514-524

Medlin LK, Kooistra WHCF, Gersonde R, Wellbrock U (1996) Evolution of the diatoms (Bacillariophyta). II. Nuclearencoded small-subunit rRNA sequence comparisons confirm a paraphyletic origin for the centric diatoms. Mol Biol Evol 13:67-75

Meijer L, Azzi L, Wang JYJ (1991) Cyclin B targets p34cdc2 for tyrosine phosphorylation. EMBO J 10:1545-1554

Miralto A, Barone G, Romano G, Poulet SA and 7 others (1999) The insidious effect of diatoms on copepod reproduction. Nature 402:173-176

Müller-Navarra DC (1995) Evidence that a highly unsaturated fatty acid limits Daphnia growth in nature. Arch Hydrobiol 132:297-307

Müller-Navarra DC, Brett MT, Liston AM, Goldman CR (2000) A highly unsaturated fatty acid predicts carbon transfer between primary producers and consumers. Nature 403:74-77

Page RD (1996) TreeView: an application to display phylogenetic trees on personal computers. Comput Appl Biosci 12:357-358

Pesando D, Graillet C, Braekman JC, Dubreuil A, Girard JP, Puiseux-Dao S (1990) The use of sea urchin eggs as a model to investigate the effects of crassolide, a diterpene isolated from a soft coral. In: Reinhardt CA, Blaauboer BJ (eds) Proc 6th Int Workshop In Vitro Toxicol. Pergamon Press, Tarritown, p 395-401

Pohnert G (2000) Wound-activated chemical defense in unicellular planktonic algae. Angew Chem Int Ed Engl 39: $4352-4354$

Pohnert G (2002) Phospholipase $A_{2}$ activity triggers the wound-activated chemical defence in the diatom Thalassiosira rotula. Plant Physiol 129:103-111

Pohnert G, Boland W (1996) Biosynthesis of the algal pheromone hormosirene by the freshwater diatom Gomphonema parvulum (bacillariophyceae). Tetrahedron 52: 10073-10082

Pohnert G, Boland W (2002) The oxylipin chemistry of attraction and defense in brown algae and diatoms. Nat Prod Rep 19:108-122

Poulet SA, Ianora A, Miralto A, Meijer L (1994) Do diatoms arrest embryonic development in copepods? Mar Ecol Prog Ser 111:79-96

Poulet SA, Laabir M, Ianora A, Miralto A (1995) Reproductive response of Calanus helgolandicus. I. Abnormal embryonic and naupliar development. Mar Ecol Prog Ser 129: $85-95$

Refsgaard HHF, Tsai L, Stadtman ER (2000) Modifications 
of proteins by polyunsaturated fatty acid peroxidation products. Proc Natl Acad Sci USA 97:611-616

Rodriguez-Ruiz J, Belarbi EH, Sanchez JLG, Alonso DL (1998) Rapid simultaneous lipid extraction and transesterification for fatty acid analyses. Biotechnol Tech 12:689-691

Saitou N, Nei M (1987) The neighbour-joining method: a new method for reconstructing phylogenetic trees. Mol Biol Evol 4:406-425

Schotten T, Boland W, Jaenicke L (1985) Synthesis of enantiomerically pure pheromones of South Pacific brown algae-hormosirene and dictyopterene A. Helv Chim Acta 68:1186-1192

Sogin ML, Gunderson JH (1987) Structural diversity of eukaryotic small subunit ribosomal RNAs. Evolutionary implications. Ann NY Acad Sci 503:125-139

Støttrup JG, Jensen J (1990) Influence of algal diet on feeding and egg-production of the calanoid copepod Acartia tonsa Dana. J Exp Mar Biol Ecol 141:87-105

Thompson JD, Higgins DG, Gibson TJ (1994) CLUSTAL W: improving the sensitivity of progressive multiple sequence alignment through sequence weighting, position-specific

Editorial responsibility: Otto Kinne (Editor),

Oldendorf/Luhe, Germany gap penalties and weight matrix choice. Nucleic Acids Res 22:4673-4680

van Iersel M, Ploemen J, Lo Bello M, Federici G, van Bladeren PJ (1997) Interactions of alpha,beta-unsaturated aldehydes and ketones with human glutathione s-transferase p1-1. Chem-Biol Interact 108:67-78

Vollenweider S, Weber H, Stolz S, Chetelat A, Farmer EE (2000) Fatty acid ketodienes and fatty acid ketotrienes: Michael addition acceptors that accumulate in wounded and diseased arabidopsis leaves. Plant J 24:467-476

Wendel T, Jüttner F (1996) Lipoxygenase-mediated formation of hydrocarbons and unsaturated aldehydes in freshwater diatoms. Phytochemistry 41:1445-1449

Williams R, Poulet SA (1986) Relationship between the zooplankton, phytoplankton, particulate matter and dissolved free amino acids in the Celtic Sea. Mar Biol 90: 279-284

Xu XL, Castell JD, O'Dor RK (1994) Influence of dietary lipid sources on fecundity, egg hatchability and fatty acid composition of Chinese prawn (Penaeus chinensis) broodstock. Aquaculture 119:359-370

Submitted: January 15, 2002; Accepted: July 26, 2002

Proofs received from author(s): November 21, 2002 